\title{
Ultrasonographic findings in dogs diagnosed with hyperadrenocorticism - retrospective study (2013 to 2020)
}

\author{
Achados ultrassonográficos em cães diagnosticados \\ com hiperadrenocorticismo - estudo retrospectivo (2013 a 2020)
}

\author{
Evelly Lopes Bueno ${ }^{*}$ (D), Victor José Vieira Rossetto² (D), Felipe Gazza Romão (i)
}

\begin{abstract}
Hyperadrenocorticism is a relatively common endocrinopathy in middle-aged and older dogs, which has become increasingly frequent in the clinical routine. The diagnosis is made by information obtained by history, physical exam findings and results of screening and specific endocrine tests. In addition to laboratory tests, imaging diagnosis, such as ultrasound, can aid on evaluation of possible changes in these cases; also, they may reveal the possible involvement of other organs and systems. The aim of this study was to present the main ultrasonographic changes observed in 18 dogs with hyperadrenocorticism, diagnosed from 2013 to 2020 by the low-dose dexamethasone suppression test, among which hepatomegaly, splenomegaly, gallbladder sludge, renal changes, cystitis and changes in adrenal size, such as bilateral and/or unilateral adrenomegaly, can be cited. Ultrasound examination, therefore, is an examination that can help the clinician in confirming the diagnosis of hyperadrenocorticism, in addition to allowing differentiation between pituitary-dependent hyperadrenocorticism (PDH) and adrenal tumors, and the evaluation of possible secondary changes to the disease.
\end{abstract}

KEYWORDS: Adrenal; Cortisol; Glucocorticoids; Hepatomegaly; Ultrasound.

\begin{abstract}
RESUMO: Hiperadrenocorticismo é uma endocrinopatia relativamente comum em cães de meia idade e idosos, que tem se tornado cada vez mais frequente na rotina clínica $\mathrm{O}$ diagnóstico é confirmado por informaçôes obtidas pelo histórico, achados de exame físico e resultados de exames de triagem e endócrinos específicos. Além dos exames laboratoriais, os exames de imagem, como a ultrassonografia, podem auxiliar na avaliação de possíveis alteraçóes nesses casos; ademais, eles também podem revelar o possível envolvimento de outros órgãos e sistemas. O objetivo deste estudo foi apresentar as principais alterações ultrassonográficas observadas em 18 cães com hiperadrenocorticismo, diagnosticados de 2013 a 2020 pelo teste de supressão por dexametasona em baixa dose, dentre as quais podem ser citadas hepatomegalia, esplenomegalia, lama biliar, alteraçóes renais, cistite e alteraçóes no tamanho e formato das adrenais, como adrenomegalia bilateral e/u unilateral. A avaliação ultrassonográfica, portanto, é um exame que pode ajudar o clínico a confirmar o diagnóstico de hiperadrenocorticismo, além de ajudar a diferenciar entre hiperadrenocorticismo hipófise-dependente (HHD) e tumores adrenais, e na avaliação de possíveis alterações secundárias à doença.
\end{abstract}

PALAVRAS-CHAVE: Adrenal; Cortisol; Glicocorticoides; Hepatomegalia; Ultrassom.

\section{INTRODUCTION}

Hyperadrenocorticism (HAC), also called Cushing's Disease, is an endocrine disease that has become increasingly common in dogs (BENNAIM; SHIEL; MOONEY, 2019a). It mainly affects adult and elderly dogs due to changes in adrenals that mostly range from functional adrenal tumors (MARTIN, 2001) to problems of overproduction of the adrenocorticotrophic hormone (ACTH) by pituitary gland, also known as pituitary-dependent hyperadrenocorticism (PHD) (SANDERS; KOOISTRA; GALAC, 2018).

Chronic excessive release of cortisol causes several changes (MARTIN, 2001). Usually, the dog has clinical signs such as: polyuria (PU) and polydipsia (PD), polyphagia, obesity, bulging/dilated abdomen, myasthenia, lethargy, dyspnea, 
symmetrical and bilateral alopecia, seborrhea, pruritus and skin hyperpigmentation (FELDMAN, 1997).

The diagnosis of hyperadrenocorticism is still considered challenging, as it is based on history, clinical signs, laboratory tests, possible adrenal function tests and imaging diagnosis (BENNAIM; SHIEL; MOONEY, 2019b).

When associated with clinical signs and laboratory tests, imaging tests are of great importance for confirming the diagnosis of HAC. It is possible to differentiate PHD and adrenal tumors by ultrasonographic findings. It has been reported that dogs with PDH commonly have bilateral adrenomegaly, while dogs with adrenal tumor present asymmetric adrenals (BENNAIM; SHIEL; MOONEY, 2019a). The differentiation of these two forms of HAC is necessary to establish appropriate therapy and prognosis (BARGELLINI et al., 2013).

In addition, other commonly changes observed on abdominal ultrasound of dogs with HAC are: hepatomegaly, splenomegaly, and gallbladder mucocele (KEALY; MCALLISTER; GRAHAM, 2012; MARTINS et al., 2019).

The objective of this paper was to correlate ultrasonographic findings in dogs diagnosed with hyperadrenocorticism by dexamethasone suppression test, in order to characterize the main ultrasonographic changes resulting from this disease.

\section{MATERIAL AND METHODS}

A retrospective study was conducted, in which 18 dogs were evaluated, all of them presenting clinical signs and posteriorly diagnosed with HAC by low dose dexamethasone suppression test. The patients underwent abdominal ultrasound examination at the time of diagnosis.

The patients were admitted at Endocrinology service of Laboratório Veterinário Edan and Endocardiovet, both located in Bauru/SP, from 2013 to 2020.

Data, including gender, breed and age, as well as abdominal ultrasound findings, such as dimensions, echotexture and echogenicity, were obtained from their ultrasonographic reports.

All patients were prepped before ultrasound examination, which involved the administration of Simethicone ( $1 \mathrm{drop} / \mathrm{kg}$, 3 times before the evaluation), and food withdrawal during 12 hours. Water intake was kept normal before the examination. The ultrasound was performed with a Mindray device, model F5, with convex and linear multifrequency transducers, and evaluation with color Doppler, as needed.

\section{RESULTS AND DISCUSSION}

Females were more affected (15/18 [83.3\%]) than male dogs $(3 / 18[16,6 \%])$. There are many contradictions regarding the predisposition of females to the diagnosis of hyperadrenocorticism. Most studies report that females are more susceptible to $\mathrm{PDH}$, functional adrenal tumor, or hyperadrenocorticism without defined cause, while other studies have not identified a difference in relation to gender predisposition; therefore, it can be considered that it is still unclear whether there is gender predisposition related to hyperadrenocorticism (BENNAIM; SHIEL; MOONEY, 2019a).

In a study conducted by Carotenuto et al. (2019), 104 dogs diagnosed with $\mathrm{HAC}$ were evaluated; among them, 19.4\% were intact females, $43.3 \%$ were spayed females, $29.8 \%$ were intact males and $7.7 \%$ were neutered males. In general, besides neutering status, $62.7 \%$ were female and $37.5 \%$ were males. O'Neill et al. (2016) state that, although some studies have already reported that females are more predisposed to hyperadrenocorticism, the result of their study does not support this hypothesis, stating that gender is not a major factor for higher odds of Cushing's syndrome, corroborating what is stated by Carotenuto et al. (2019), who observed that $83.3 \%$ of the animals affected by HAC were females, which shows greater sexual predisposition for females; however, it is not yet possible to justify it, since most of these females were neutered, what could be the actual predisposing factor.

In addition, our study confirmed the reproductive status of 14 patients according to ultrasonographic reports. Of these, one was a spayed male, nine were neutered females and four females were intact. Therefore, it can be noted that neutered animals presented greater predisposition to the development of HAC. Although some authors claim that neutered animals are more predisposed to the occurrence of hyperadrenocorticism, this relationship cannot yet be proven; in fact, it is believed that it is due to the longer life expectancy of neutered animals, than to a direct influence on the disease (HOFFMAN et al., 2018).

Regarding the age of the affected dogs, we observed that middle-aged to elderly dogs presented a higher predisposition to hyperadrenocorticism, since the age of patients ranged from eight to 13 years old (mean $10.3 \pm 2.95$ ). In general, dogs affected with PDH are middle-aged to elderly, ranging from 2 years in some cases, up to 16 years, but usually the average age is 7 to 9 years. Dogs with adreno-dependent hyperadrenocorticism are commonly older, with ages ranging from six to 16 years old (mean: 11.3 years), what may be justified by the fact that older dogs have a greater predisposition to neoplasms (MARTINS et al., 2019). In the present study, it was possible to conclude that the age of dogs diagnosed with $\mathrm{HAC}$ is in accordance with the literature, because the animals reported here are middle-aged to elderly.

According to the survey of breeds affected by hyperadrenocorticism in the present study, it was possible to observe that Poodles and Yorkshire terriers were the most affected, followed by Maltese, Shih tzu and Pinscher (two animals each), while only one Labrador retriever and Mongrel dog were reported (Table 1).

Some breeds are more predisposed to be affected by PDH, thus Poodle, Teckel, Beagle, Terriers, Yorkshire terrier, Labrador retriever, Boxer and German shepherd are overrepresented (JERICÓ; NETO; KOGIKA, 2015). Carotenuto et al. (2019) reported that the Schnauzer, Fox Terrier, Cavalier Spaniel, 
Table l. Animals diagnosed with HAC by low dose dexamethasone suppression test according to breed $(\mathrm{N}=18)$.

\begin{tabular}{l|c} 
Breed & Number \\
\hline Poodle & 5 \\
\hline Yorkshire terrier & 5 \\
\hline Maltese & 2 \\
\hline Shih tzu & 2 \\
\hline Pinscher & 2 \\
\hline Labrador retriever & 1 \\
\hline Mongrel & 1 \\
\hline TOTAL & 18 \\
\hline
\end{tabular}

Boxer, Shih Tzu, Pit bull, Jack Russel terrier, Maltese, Teckel and Yorkshire Terrier have a significantly higher risk of developing hyperadrenocorticism when compared to mongrel dogs. The data of the present study agree with the authors cited, because it was observed that most of the animals affected with HAC are Poodle and Yorkshire terrier dogs.

Abdominal ultrasound evaluations were performed in all patients, and changes in organs such as liver, gallbladder, spleen, kidneys, bladder and adrenals were observed in some animals. Most dogs presented liver changes (Table 2), as hepatomegaly was observed in $72.2 \%$ of the animals, thus being the most frequent alteration in the animals included in this study.

Hepatomegaly, a relatively common finding in animals with HAC, may be justified by glucocorticoide-induced alteration, which commonly causes progressive hepatocellular edema; in addition, vacuolar hepatopathy can occur, in which hepatocytes are distended by glycogen deposition (GUPTILL; SCOTT-MONCRIEFF; WIDMER, 1997). Generalized hepatic enlargement can often be characterized by rounded contours, and irregular margins may be present when nodules occur (KEALY; MCALLISTER; GRAHAM, 2012). It is also possible to observe changes in echotexture and echogenicity, with hyperechogenic or hypoechogenic patterns. Generalized increase in echogenicity may occur due to fatty infiltration, lymphoma, cirrhosis, or steroid-mediated liver disease (Figure 1). Hepatic veins become distended, often because of the presence of hepatic fibrosis (KEALY; MCALLISTER; GRAHAM, 2012). Hepatomegaly was observed in $72.2 \%$ of the animals analyzed in this study; in addition, some findings mentioned above, such as changes in echotexture and echogenicity, were observed in $27.7 \%$ of dogs, which may be secondary to the excess of glucocorticoids (BENNAIM et al., 2019a).

Regarding the gallbladder, some dogs presented it filled with biliary sludge, while others presented thin walls, and one animal presented biliary mucocele (Table 3 ).

Many authors suggest that endocrinopathies such as hyperadrenocorticism and hypothyroidism may predispose to the development of pathological changes in the gallbladder
Table 2. Animals diagnosed with HAC by the low dose dexamethasone suppression test and the liver changes found on abdominal ultrasound examination $(n=18)$.

\begin{tabular}{l|c} 
Changes & Number \\
Enlarged size - hepatomegaly & $13(72,2 \%)$ \\
\hline Coarse hepatic echotexture & $5(27,7 \%)$ \\
\hline $\begin{array}{l}\text { Heterogeneous hypoechoic micronodular } \\
\text { echotexture - vacuolar hepatopathy }\end{array}$ & $5(27,7 \%)$ \\
\hline Enhanced echogenicity & $5(27,7 \%)$ \\
\hline Dilated vascular pattern - congestion & $4(22,2 \%)$ \\
\hline Irregular surfaces & $2(11,1 \%)$ \\
\hline Irregular borders & $2(11,1 \%)$ \\
\hline Fatty infiltration & $1(5,5 \%)$ \\
\hline Rounded contours & $1(5,5 \%)$ \\
\hline
\end{tabular}

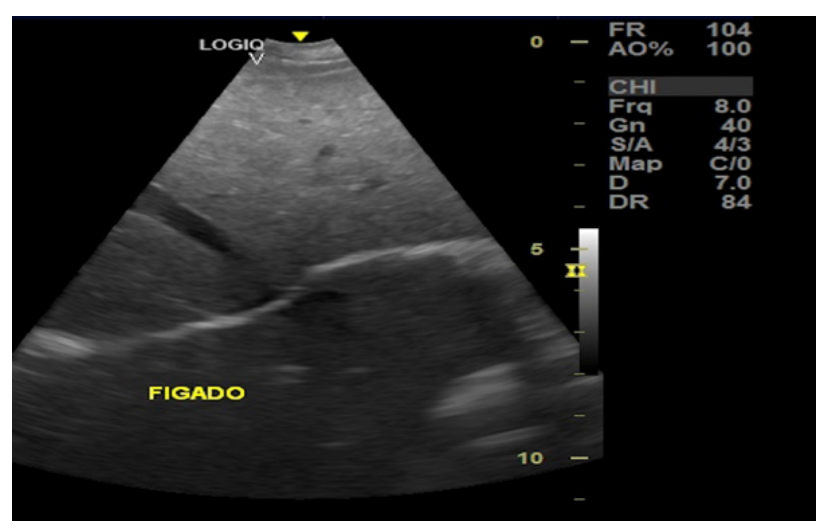

Figure 1. Ultrasound image of the liver. Note the irregular contours, blunt edges, heterogeneous/coarse parenchyma and increased echogenicity with discrete foci of beam attenuation in the dorsal region.

Table 3. Animals diagnosed with HAC by the low dose suppression test of dexamethasone and the changes observed in the gallbladder found on abdominal ultrasound examination $(n=18)$.

\begin{tabular}{l|c}
\hline Alterations & Number \\
\hline Biliary sludge & $8(44,4 \%)$ \\
\hline Thin walls & $4(22,2 \%)$ \\
\hline Biliary mucocele & $1(5,5 \%)$ \\
\hline
\end{tabular}

(MESISH et al., 2009), which could be explained by a possible association with the alterations found in the patients used in this study. Mucocele is caused by excessive accumulation of intraluminal bile or formation of biliary sludge that is improperly stored in the gallbladder, which causes biliary obstruction and consequent distension of the gallbladder, and, at worst, gallbladder rupture. Dogs with hyperadrenocorticism are 29 times more likely to develop gallbladder mucocele (Figure 2) (SMALLE; CAHALANE; KÖSTER, 2015). Conversely, a study was conducted in which Beagles received exogenous steroid administration 2 times a day for approximately three months, in order to recreate a hyperadrenocorticism scenario, 


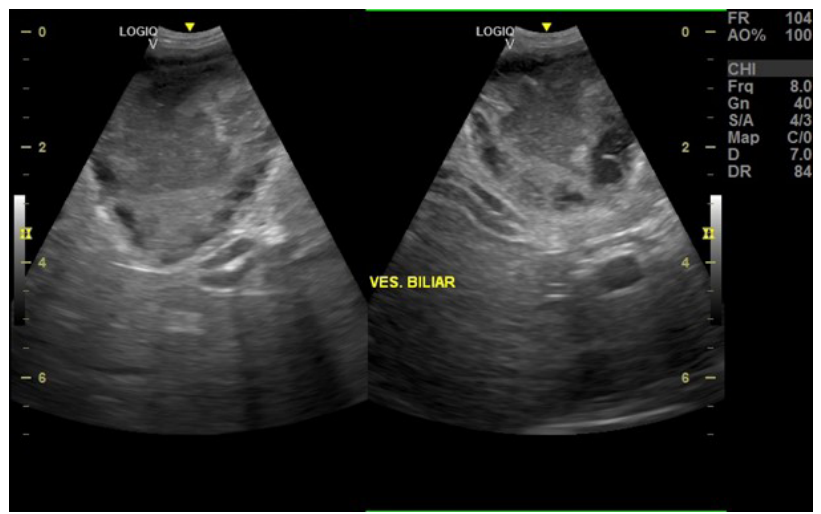

Figure 2. Ultrasound image of the gallbladder, filled with liquid anechoic content, with a marked amount of hyperechogenic content occupying the entire gallbladder and tending to star-shape in the periphery (mucocele). Thin walls also can be observed.

in which it was possible to observe that iatrogenic hypercorticolism did not cause ultrasound changes related to the gallbladder, except for the presence of biliary sludge (KOOK et al., 2012). The information cited by these authors corroborates the ultrasound findings found in dogs demonstrated in our study, in which $44.4 \%$ had the presence of biliary sludge, and $22.2 \%$ had wall thinning, which may indicate gallbladder distension.

Regarding the findings associated with the spleen, it was possible to observe that the most common change was splenomegaly $(72.2 \%$ of the animals), followed by anechoic circumscribed image (11.1\%), suggestive of splenic hematoma (Table 4).

Neoplasms and splenic lesions are major causes of splenomegaly. Commonly nodules and masses are found through ultrasound examinations. Splenic neoplasms can be represented with areas of mixed or hypoechoic echogenicity. In addition to nodules, splenic hematomas may be found, which in the initial phase presents as a hyperechoic image; when it begins to regress may become hypoechoic and in the phase of clot retraction may present as an aspect of anechoic fluid. The "target-lesion" usually occurs as a circumscribed image, with hypoechogenic border and hyperechogenic center. This is the most consistent finding related to neoplasms, but this can only be confirmed by fine needle aspiration cytology or biopsy (KEALY; MCALLISTER; GRAHAM, 2012). All changes described by Kealy, Mcallister and Graham (2012) were noted in the ultrasound findings of the animals in this study. As mentioned, such alterations are commonly indicative of neoplasia; however, its relationship with HAC is still unclear.

Among the findings related to the kidneys, it was possible to observe alterations such as cortical rim sign, loss of definition in the corticomedullary junction, changes in echogenicity, among others, presented in Table 5.

The excess of glucocorticoids results in harmful changes to the kidneys. Dogs with hyperadrenocorticism are likely to develop chronic kidney disease (CKD). A study conducted
Table 4. Animals diagnosed with HAC by the low dose dexamethasone suppression test and the splenic changes found on abdominal ultrasound examination ( $n=18)$.

\begin{tabular}{l|c}
\hline Alterations & Number \\
\hline Enlarged size - splenomegaly & $13(72,2 \%)$ \\
\hline Anechoic circumscribed image & $2(11,1 \%)$ \\
\hline $\begin{array}{l}\text { Oval formation characterized by } \\
\text { homogeneous echotexture, hyperechoic } \\
\text { echogenicity, without vascularization }\end{array}$ & $1(5,5 \%)$ \\
\hline $\begin{array}{l}\text { Oval formation characterized by } \\
\text { homogeneous echotexture, hypoechoic } \\
\text { echogenicity, without vascularization }\end{array}$ & $1(5,5 \%)$ \\
\hline $\begin{array}{l}\text { Heterogeneous formation with anechoic } \\
\text { center, without vascularization }\end{array}$ & $1(5,5 \%)$ \\
\hline $\begin{array}{l}\text { Spherical structure with “target” aspect, } \\
\text { with discrete vascularization }\end{array}$ & $1(5,5 \%)$ \\
\hline
\end{tabular}

Table 5. Animals diagnosed with HAC by the low-dose dexamethasone suppression test and the renal changes found on abdominal ultrasound examination ( $n=18)$.

\begin{tabular}{l|c} 
Alterations & Number \\
\hline Increased cortical echogenicity & $8(44,4 \%)$ \\
\hline Bilateral rim sign & $6(33,3 \%)$ \\
\hline Loss of corticomedullary definition & $5(27,7 \%)$ \\
\hline Cystic structures & $4(22,2 \%)$ \\
\hline Kidney urolith & $2(11,1 \%)$ \\
\hline Cortical thickening & $1(5,5 \%)$ \\
\hline Microcrystals & $1(5,5 \%)$ \\
\hline
\end{tabular}

with 25 dogs diagnosed with Cushing's syndrome was able to identify marked glomerular and tubular dysfunction when compared to healthy dogs (SMETS et al., 2010). It is possible to observe on ultrasound examination of dogs on stage IV of chronic kidney disease the loss of corticomedullary definition, in addition to increased cortical and medullary echogenicity.

Nephrocalcinosis is also a very common finding in dogs with hyperadrenocorticism, mainly characterized by increased cortical echogenicity and formation of a hyperechoic margin or rim in the corticomedullary junction region, known as "medullary rim sign" (KEALY; MCALLISTER; GRAHAM, 2012). All animals used in this study presented high levels of circulating cortisol, measured through the low dose dexamethasone suppression test, and those who had in the cortisol test $4 \mathrm{~h}$ and/or $8 \mathrm{~h}$ post dexamethasone greater than $1.0 \mu \mathrm{g} / \mathrm{dL}$; therefore, the information described in the literature is able to support the ultrasonographic findings of these dogs, which can most likely be justified by glucocorticoid-induced kidney disease. 
Regarding the ultrasonographic findings related to the bladder, the most common alteration (22.2\%) was wall thickening, which is a great indication of cystitis. Bladder uroliths were observed in $11.1 \%$ of dogs (Table 6).

Nichols (1997) states that high plasma cortisol levels trigger recurrent cases of urinary tract infection and urolithiasis. The action of glucocorticoids in the body causes decreased resistance to infections. Chronic processes tend to facilitate the formation of urolithiasis by struvite and the action of cortisol under calcium secretion may predispose to calcium uroliths. Glucocorticoids cause sodium and water retention, in addition to inhibiting the secretion of antidiuretic hormone, causing the bladder to be always full (may cause polyuria or even urinary incontinence), thus also predisposing to lower urinary tract infections and uroliths formation (SMETS et al., 2010). In a study conducted by Gilor and Graves (2011), it was reported that $50 \%$ of dogs with hyperadrenocorticism had lower urinary tract infection. In these cases, the bladder wall appears thickened. As previously reported, ultrasound findings in these dogs may be justified by the effect of excess glucocorticoids on the body. The presence of cystitis, uroliths and sediment corroborate what was reported by the authors and can be justified through it.

Ultrasonographic images of the adrenals found bilateral adrenomegaly in $50 \%$ of the animals, while some presented poorly defined contours and hypoechoic echotexture (Table 7).

Behrend et al. (2013) state that dogs with PDH commonly have symmetrical and normal-sized or enlarged adrenal glands. Conversely, Bennaim et al. (2019a) indicate that bilateral adrenomegaly (Figure 3) is usually observed in dogs with $\mathrm{PDH}$, and unilateral adrenomegaly and asymmetry is expected in dogs with functional adrenal tumor, but these changes are not necessarily mandatory. These findings were observed in animals used in this study, since $50.0 \%$ presented bilateral adrenomegaly and a small percentage presented unilateral adrenomegaly, as $2(11.1 \%)$ patients presented enlargement of left adrenal, and only $1(5.5 \%)$ had an increase in the right adrenal. Symmetry or asymmetry was not reported in the ultrasound findings of these patients; also, 2 (11.1\%) patients presented adrenals of normal size, and in 1 (5.5\%) patient it was not possible to visualize the adrenals because the dog was very tense.

Usually dogs that present unilateral adrenomegaly, irregular or little defined contours, heterogeneous echotexture, mineralization foci and atrophy of the opposite gland have a strong suspicious of an adrenal tumor (JERICÓ; NETO; KOGIKA, 2015). Mineralization foci on the adrenal gland is observed in most animals with adrenal tumor. In addition, the architecture is damaged, resulting in hypoechoic foci (GUPTILL et al., 1997). Poorly defined contours was observed in $27.7 \%$ of dogs, in addition to mineralization foci (5.5\%), which may indicate adrenal tumor; however, this suspicion could not be
Table 6. Animals diagnosed with HAC by the low-dose dexamethasone suppression test and the bladder changes found on abdominal ultrasound examination ( $n=18)$.

\begin{tabular}{l|c} 
Alterations & Number \\
\hline Thickened wall & $4(22,2 \%)$ \\
\hline Thinned wall & $2(11,1 \%)$ \\
\hline Bladder uroliths & $2(11,1 \%)$ \\
\hline Sediment & $1(5,5 \%)$ \\
\hline
\end{tabular}

Table 7. Animals diagnosed with HAC by low-dose dexamethasone suppression test and adrenal changes found on abdominal ultrasound examination ( $n=18)$.

\begin{tabular}{l|c}
\hline Changes & Number \\
\hline Bilateral adrenomegaly & $9(50,0 \%)$ \\
\hline Poorly defined contours & $5(27,7 \%)$ \\
\hline Hypoechoic echotexture & $3(16,6 \%)$ \\
\hline Unilateral adrenomegaly & $3(16,6 \%)$ \\
\hline Irregular shape/nodular appearance & $1(5,5 \%)$ \\
\hline Mineralization foci on cranial pole & $1(5,5 \%)$ \\
\hline
\end{tabular}

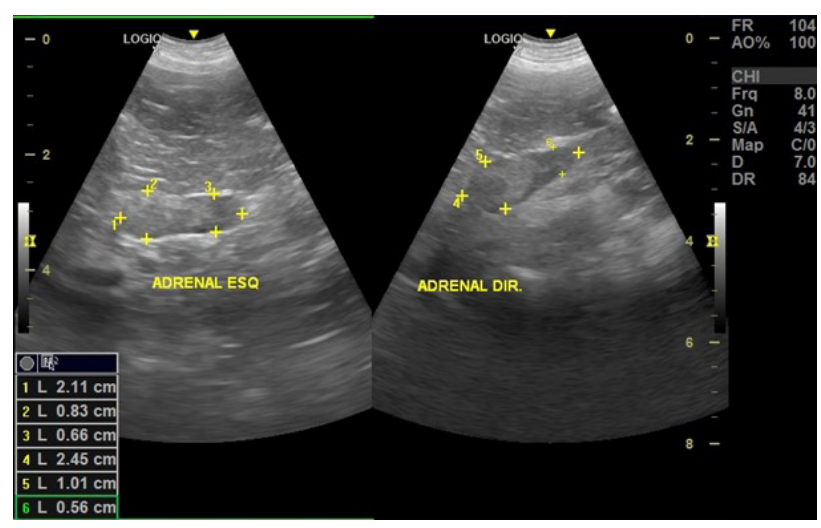

Figure 3. Ultrasonographic images of topical enlarged adrenals, with loss of corticomedullary definition. The shape was preserved, but rounded edges and heterogeneous parenchyma could be observed. The right adrenal has a preserved shape and homogeneous parenchyma, except for the visualization of nodular and hyperechoic structure in cranial pole measuring $1.0 \times 0.7 \mathrm{~cm}$ in diameter.

confirmed because no mass was observed or cytology/histopathology was performed to confirm the presence of a tumor.

\section{CONCLUSION}

The changes observed in animals diagnosed with HAC mainly involve the liver, gallbladder, spleen, kidneys, urinary bladder and adrenals. These organs are greatly influenced by excess circulating cortisol in the body, resulting in changes in echotexture and echogenicity, increased dimensions, loss of definition and structure, changes in wall thickening, among others reported above. Imaging diagnosis can, therefore, aid to confirm the diagnosis of HAC, considering that it is a condition influenced by several other conditions and that may have the interpretation of hormonal tests impaired. 


\section{REFERENCES}

BEHREND, E. N., et al. Diagnosis of Spontaneous Canine Hyperadrenocorticism: 2012 ACVIM Consensus Statement (Small Animal). Journal of Veterinary Internal Medicine, v. 27, п. 6, p. 1292-1304, 2013.

BENNAIM, M.; SHIEL, R.; MOONEY, C. T. Diagnosis of spontaneous hyperadrenocorticism in dogs. Part l: Pathophysiology, aetiology, clinical and clinicopathological features. Veterinary journal, v. 252 , 2019.a

BENNAIM, M.; SHIEL, R.; MOONEY, C. T. Diagnosis of spontaneous hyperadrenocorticism in dogs. Part 2: Adrenal function testing and differentiating tests. Veterinary journal, v. $252,2019.6$

CAROTENUTO, G., et al. Cushing's syndrome - an epidemiological study based on a canine population of 21.281 dogs. Open Veterinary Journal, v. 9, n. 1, p. 27-32, 2019.

FELDMAN, E. C. Hiperadrenocorticismo. In: ETTINGER, S. J.; FELDMAN, E. C. Tratado de medicina interna veterinária, moléstias do cão e do gato. 4. ed. v. 2, p. 2123-2177. São Paulo: Editora Manole, 1997.

GILOR, C.; GRAVES, T.K. Interpretation of laboratory tests for canine Cushing's syndrome. Topics in companion animal medicine, v. 26, п. 2, p. 98-108, 2011.

GUPTILL, L.; SCOTT-MONCRIEFF, J. C.; WIDMER, W.R. Diagnosis of canine hyperadrenocorticism. The Veterinary clinics of North America: Small animal practice. v. 27, n. 2, p. 215-235, 1997.
HOFFMAN, J.M., et al. Canine hyperadrenocorticism associations with signalment, selected comorbidities and mortality within North American veterinary teaching hospitals. Journal of Small Animal Practice, v. 59, n. 11, p. 681-690, 2018.

KOOK, P.H., et al. Effects of iatrogenic hypercortisolism on gallbladder sludge formation and biochemical bile constituents in dogs. The Veterinary Journal, v. 191, n. 2, p. 225-230, 2012.

MARTINS, F. S. M., et al. Epidemiological, clinical, and laboratory aspects in a case series of canine hyperadrenocorticism: 115 cases (2010-2014). Pesquisa Veterinária Brasileira, v. 39, п. 11, 2019.

NICHOLS, R. Complications and concurrent disease associated with canine hyperadrenocorticism. The Veterinary clinics of North America. Small animal practice, v. 27, n. 2, p. 309-320, 1997.

O'NEILL, D.G., et al. Epidemiology of hyperadrenocorticism among 210,824 dogs attending primary-care veterinary practices in the UK from 2009 to 2014. The Journal of Small Animal Practice, v. 57, п. 7, р. 365-373, 2016.

SANDERS, K.; KOOISTRA, H. S.; GALAC, S. Treating canine Cushing's syndrome: Current options and future prospects. Veterinary Journal, v. 24l, p. 42-51, 2018.

SMALLE, T. M.; CAHALANE, A. K.; KÖSTER, L. S. Gallbladder mucocele: A review. Journal of the South African Veterinary Association, v. 86, n. 1, 2015.

SMETS, P., et al. Cushing's syndrome, glucocorticoids and the kidney. General and comparative endocrinology. v. 169, n. 1, p. 1-10, 2010. 